\title{
Anaortic Off-Pump Complete Arterial Revascularization Using Composite LIMA RIMA Y Sequential 5 Grafts in a Patient with Triple Vessel Disease Performed in a Low Resource Country: A Case Report
}

\author{
Asraful Hoque ${ }^{*}$, Romena Rahman', Abu Shadat Mohammad Saem Khan', Md. Abdullah Yusuf', \\ Muhammad Asif Ahsan Chowdhury', Imran Ahmed', Wahida Salam¹, Md. Monzur Hossain', \\ Tanvir Hossain ${ }^{1}$
}

\begin{abstract}
${ }^{1}$ Department of Cardiac Surgery, National Institute of Cardiovascular Diseases, Dhaka, Bangladesh
${ }^{2}$ Department of Microbiology, National Institute of Neurosciences and Hospital, Dhaka, Bangladesh

Email: ^dr_asraf_sium@yahoo.com,drromena@gmail.com, saemkhan1986@gmail.com,

ayusuf75@yahoo.com,dr_asifahsanchy@yahoo.com,imrandinajcs@gmail.com,dr.wahida.salam@gmail.com,

monzurhossain.jony@gmail.com, tanvir67678@gmail.com
\end{abstract}

How to cite this paper: Hoque, A., Rahman, R., Khan, A.S.M.S., Yusuf, M.A., Chowdhury, M.A.A., Ahmed, I., Salam, W., Hossain, M.M. and Hossain, T. (2021) Anaortic Off-Pump Complete Arterial Revascularization Using Composite LIMA RIMA Y Sequential 5 Grafts in a Patient with Triple Vessel Disease Performed in a Low Resource Country: A Case Report. World Journal of Cardiovascular Surgery, 11, 125-132. https://doi.org/10.4236/wjcs.2021.1112016

Received: September 9, 2021

Accepted: December 26, 2021

Published: December 29, 2021

Copyright $\odot 2021$ by author(s) and Scientific Research Publishing Inc. This work is licensed under the Creative Commons Attribution-NonCommercial International License (CC BY-NC 4.0). http://creativecommons.org/licenses/by-nc/4.0/ (c) (i) (5) Open Access

\begin{abstract}
The use of bilateral internal thoracic arteries to treat coronary artery disease is very less despite of improved long-term survival. In this case report, a patient presented with TVD has been managed with anaortic off-pump complete arterial revascularization (OPCABG) by using composite LIMA RIMA Y Sequential 5 grafts to achieve complete arterial revascularization successfully. This type of operative procedure is technically difficult in a resource poor country like Bangladesh. However, this has been done by a group of young cardiac surgeon. During follow up, the patient is in a good condition.
\end{abstract}

\section{Keywords}

Anaortic, Off-Pump, Complete Arterial Revascularization, Composite LIMA RIMA Y Sequential 5 Grafts, Triple Vessel Disease, Low Resource Country

\section{Introduction}

The most widely utilized coronary artery bypass grafting (CABG) technique remains the left internal mammary artery (LIMA) to the left anterior descending (LAD) artery and reversed long saphenous vein (LSV) from the aorta to other 
arteries, performed using cardiopulmonary bypass on an arrested heart [1]. However, there are 2 significant drawbacks to this widely performed technique. Firstly, there is now an established relationship between the degree of aortic manipulation and the risk of neurological injury. In a large network meta-analysis performed comparing all techniques (on-pump CABG with an aortic cross-clamp, off-pump CABG with a partial occlusion clamp, off-pump CABG with a proximal anastomotic device and "anaortic" off-pump CABG with no aortic manipulation), the anaortic technique was shown to be the most effective method for decreasing the risk of stroke [2]. It also reduced the risk of mortality, renal failure, bleeding complications and other morbidity [3]. The second drawback to the traditional technique is the known failure rate, both early and late, of LSV grafts [4]. In contrast, the benefits of multi-arterial grafting (MAG), using the right internal mammary artery (RIMA) and/or radial artery, on long-term patient survival, have been known for more than 2 decades [5].

Despite of improved long-term survival attained by using bilateral internal mammary arteries (BIMA) over the standard left internal mammary artery (LIMA) with saphenous vein grafts (SVG) supported by recent literatures [1] [2] [3] [4], the use of BIMA is very less in reality [5] [6]. Since Barn \& Barnett [7], Tector et al. [8] and Barr et al. [9] proposed Y or T graft procedure done by anastomosing the proximal end of the free RIMA to the side of the in situ LIMA, that provides an extra length to facilitate reaching the distal coronary artery branches, issues of complete arterial revascularization using BIMA made a way out. Kamath et al. [10] and Chocron et al. [11] were first to report their experiences using BIMA grafts in off-pump coronary artery bypass grafting (OPCABG) setting which subsequently become more popular to avoid cardiopulmonary bypass (CPB) related complications. We present here a patient with triple vessel disease (TVD) on whom an aortic OPCABG using composite LIMA RIMA Y sequential grafts was performed to achieve complete arterial revascularization.

\section{Case Presentation}

A 45 years' male, normotensive, nondiabetic patient with BMI of 22.5, known case of coronary artery disease (triple vessel disease), presented with history of anteroseptal myocardial ischaemia (MI) 10 months back for elective surgical revascularization. He had past history of chest pain along with dyspnea on exertion for 6 months before the incidence. There wasn't any other significant past medical or surgical history. His coronary angiography revealed $90 \%$ to $95 \%$ stenosed left anterior descending artery (LAD) in its proximal segment, total occlusion of obtuse marginal (OM)2 in its proximal segment, $70.0 \%$ to $75.0 \%$ stenosed right coronary artery (RCA) along with $80 \%$ stenosed posterior left ventricular branch (PLV) in its mid segment (Figure 1). Echocardiography revealed antero-septal wall hypokinesia with fair left ventricular systolic function (EF $51 \%$ ), trivial mitral regurgitation (MR) and good right ventricular (RV) function (TAPSE $18 \mathrm{~mm}$ ). 


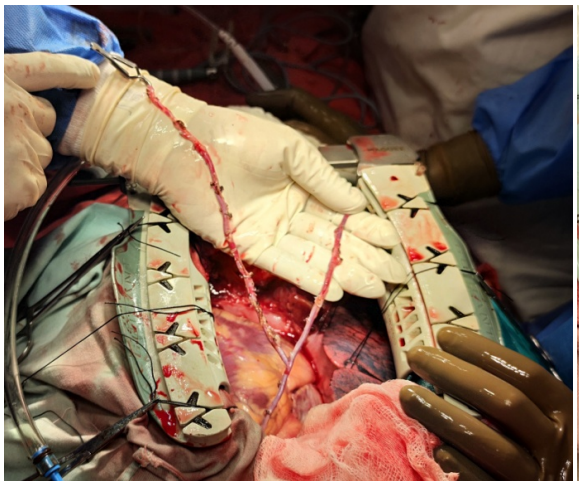

(a)

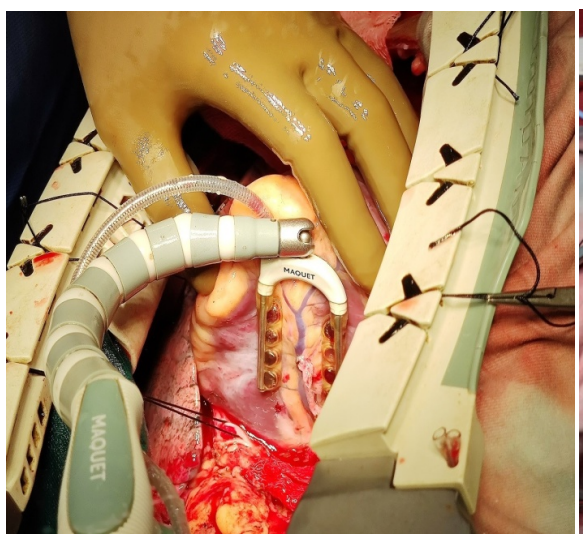

(c)

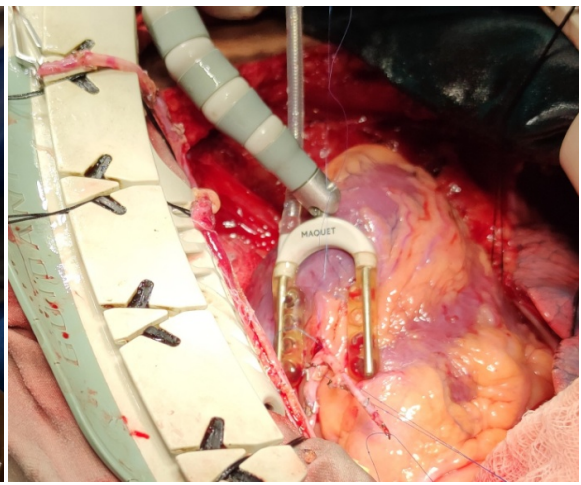

(b)

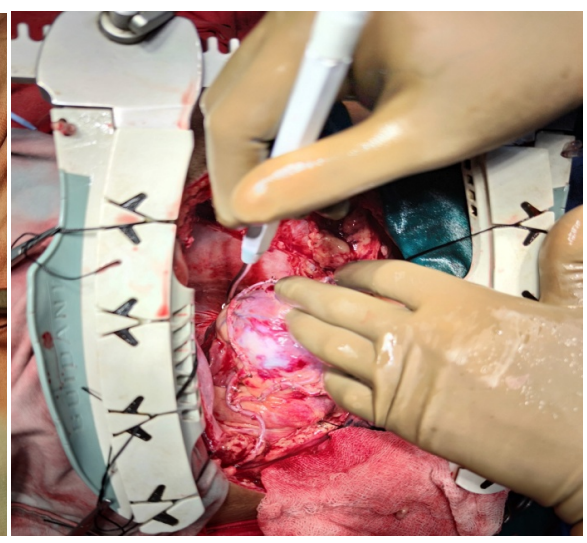

(d)

Figure 1. (a). After construction of $Y$ anastomosis, (b). LIMA to $D_{1}$ anastomosis is going on, (c). Just after construction of RIMA Y to PDA anastomosis, (d). After completion of LIMA RIMA Y grafting.

OPCABG was performed in this patient through standard median sternotomy. LIMA was harvested in skeletonized fashion while RIMA was harvested as a pedicled conduit. To ensure maximal length, both the internal mammary arteries (IMA) were tried to free much as possible between the subclavian artery proximally and bifurcation of IMA distally. When both the IMAs are freed from the chest wall, heparin administered and LIMA is divided distally. RIMA is divided both proximally and distally to make it a free graft. The LIMA RIMA end to side $\mathrm{Y}$ anastomosis constructed at the level of pulmonary annulus using 8-0 prolene suture after preparing the proximal end of LIMA as well as the rest of its length also. LIMA sequential to diagonal (D) $\mathrm{D}_{1}$ and LAD constructed using 8-0 prolene suture. Then RIMA Y sequential to $\mathrm{OM}_{2}, \mathrm{OM}_{3}$ and posterior descending artery (PDA) were made using 7-0 prolene suture (Figure 1). Postoperatively the patient had uneventful recovery and was discharged from hospital on his $7^{\text {th }}$ post-operative day.

\section{Discussion}

A Y graft is a graft which is constructed by the LIMA anastomosed to the LAD and by a free RIMA anastomosed to the LIMA proximally in an end to side 
manner which connected distally to a marginal branch of the circumflex artery, first proposed by Sauvage et al. [12]. Construction of this Y limb using LIMA and free RIMA is technically challenging but that provides an extra length to reach the distal targets, including the PDA. The use of this $\mathrm{Y}$ conduit in the revascularization of the blocked territory has several advantages. One of these is, it is ideally matched and avoid the problems of proximal anastomosis to the aorta and this "no touch" technique reduces the risk of stroke and the greater length of RIMA facilitates more extensive myocardial revascularization which helps to avoid the use of a third conduit [13]. On the other hand, as like all surgical techniques, it has some pitfalls as well. Single source blood supply with steal phenomenon, competitive flow and hypoperfusion syndrome are some of the well recognized drawbacks associated with composite grafting [14]. The "Achilles hill" of Y grafting is to graft two territories with different run-off (e.g. 90\% proximal LAD stenosis with a large territory and $50 \%$ proximal circumflex artery territory) which is responsible for lower patency rate than that of individual grafting [15]. In our case, all the target vessels had critical stenosis ( $\geq 75 \%)$.

The relative flow distribution among the grafted vessels in case of composite $\mathrm{Y}$ grafts depends on the size of the respective vascular beds and grafted vessels as well as the degree of native coronary stenosis [16]. Glineur et al. [17] conducted a study to determine the capacity of $\mathrm{Y}$ graft configuration to provide sufficient blood flow to the whole left coronary system and about possible steal phenomenon occurring during period of maximal myocardial blood flow demand. They measured fractional flow reserve (FFR) during cardiac catheterization 6 months after Y graft revascularization of the left coronary system with both IMAs in 11 consecutive patients. They found Y graft allows an adequate revascularization of the whole left coronary system with an even distribution of perfusion pressure in both distal branches and minimal resistance to maximal blood flow.

Use of BIMA was found superior over single IMA and vein grafts in a number of observational or propensity matched studies and several meta-analysis. Increased long time survival has been reported in high risk patients undergone BIMA grafting [18] [19] [20] [21]. Despite of these good results using BIMA, the use of BIMA grafting found surprisingly low among the surgeons. LaPar et al. [6] reported that, from 2001 to 2013, use of BIMA was only 3\% in the overall bypass population and $6.0 \%$ in a subgroup of patients considered "low risk" for BIMA use. An analysis of the Society of Thoracic Surgeons database revealed the use of BIMA was 3.5\% in 1999 and $4.1 \%$ in 2009 [5]. One of the reasons is the fear of sterna wound dehiscence and another one is lack of experience and fear of incomplete revascularization. Wound infection can be minimized by harvesting skeletonized IMA [22] and the aggressive control of blood glucose in diabetic patients. As well as it provides extra length that can combat the fear of incomplete revascularization. Di Mauro et al. [23] reported a better 17 years survival in patients with skeletonized BIMA grafts than in patients with pedicled BIMA grafts. We harvested LIMA as skeletonized graft while RIMA was harvested as pedicled graft. 
IMA hypoperfusion syndrome resulting from vasospasm of the arterial grafts is associated with high mortality [24]. Perioperative hypoperfusion may lead to ischaemia, infarction, low output states, profound hypotension in $1 \%-2 \%$ cases undergoing composite grafting [25]. The hypoperfusion syndrome may result from injury to the conduit during harvesting, technical errors in the anastomosis, linear tension on the conduit, angulation at the anastomotic site and unresolved harvest spasm [26]. To reduce the incidence of perioperative hypoperfusion, proper preoperative assessment of the quality of IMA graft and the subclavian artery by angiography, carefulness and adherence of meticulous surgical techniques during conduit harvesting and construction of anastomosis, insertion of $1-1.5 \mathrm{~mm}$ flexible prob into the IMA after harvesting, and flow measurement by transit time Doppler flow meter after completion of anastomosis are the key [27].

In our case, we performed 5 distal anastomoses. LIMA was grafted sequentially to $\mathrm{D}_{1}$ and LAD, while RIMA Y was grafted sequentially to $\mathrm{OM}_{2}, \mathrm{OM}_{3}$ and PDA. Gu et al. [28] performed OPCABG using LIMA RIMA Y grafts in 208 patients from October 2002 to December 2008. Their average distal anastomoses was $3.5 \pm 1.3$ per person. They found OPCABG using the BIMA Y graft was safe and effective to achieve total arterial revascularization. Another study conducted by Glineur et al. [29] from January 2000 to December 2010 among 436 patients at 2 different institutes, using the BIMA Y grafts to assess the utilization of BIMA Y in comparison to BIMA with additional vein grafts revealed improved survival with the use of BIMA Y grafts. Their average number of grafts in BIMA $\mathrm{Y}$ group and BIMA with additional vein grafts group was $4.0 \pm 0.7$ vs $4.0 \pm 0.7 ; \mathrm{p}$ $=0.24$. Di Mauro et al. [30] in their BIMA in situ vs Y graft 20 year outcome study, reported outcome of BIMA grafting is independent of surgical configuration. Y grafting increases the flexibility of BIMA grafting and should be taken into account when a surgical strategy for myocardial revascularization needs to be planned.

\section{Conclusion}

OPCABG by using LIMA RIMA Y graft is an effective option for total arterial revascularization. Adherence to meticulous surgical techniques can avoid the possible complications and also overcome the fear of incomplete revascularization despite the number of target lesions.

\section{Conflicts of Interest}

There is no conflict of interest to any of the authors.

\section{References}

[1] Grau, J.B., Ferrari, G., Mak, A.W., Shaw, R.E., Brizzio, M.E., Mindich, B.P., et al. (2012) Propensity Matched Analysis of Bilateral Internal Mammary Artery versus Single Left Internal Mammary Artery Grafting at 17-Year Follow-Up: Validation of a Contemporary Surgical Experience. European Journal of Cardio-Thoracic Sur- 
gery, 41, 770-775. https://doi.org/10.1093/ejcts/ezr213

[2] Puskas, J.D., Sadiq, A., Vassiliades, T.A., Kilgo, P.D. and Lattouf, O.M. (2012) Bilateral Internal Thoracic Artery Grafting Is Associated with Significantly Improved Long-Term Survival, Even among Diabetic Patients. The Annals of Thoracic Surgery, 94, 710-716. https://doi.org/10.1016/j.athoracsur.2012.03.082

[3] Kurlansky, P.A., Traad, E.A., Dorman, M.J., Galbut, D.L., Zucker, M. and Ebra, G. (2010) Thirty-Year Follow-Up Defines Survival Benefit for Second Internal Mammary Artery in Propensity-Matched Groups. The Annals of Thoracic Surgery, 90, 101-108. https://doi.org/10.1016/j.athoracsur.2010.04.006

[4] Weiss, A.J., Zhao, S., Tian, D.H., Taggart, D.P. and Yan, T.D. (2013) A Meta-Analysis Comparing Bilateral Internal Mammary Artery with Left Internal Mammary Artery for Coronary Artery Bypass Grafting. Annals of Cardiothoracic Surgery, 2, 390-400.

[5] ElBardissi, A.W., Aranki, S.F., Sheng, S., O’Brien, S.M., Greenberg, C.C. and Gammie, J.S. (2012) Trends in Isolated Coronary Artery Bypass Grafting: An Analysis of the Society of Thoracic Surgeons Adult Cardiac Surgery Database. The Journal of Thoracic and Cardiovascular Surgery, 143, 273-281. https://doi.org/10.1016/j.jtcvs.2011.10.029

[6] LaPar, D.J., Crosby, I.K., Rich, J.B., Quader, M.A., Speir, A.M., Kern, J.A., et al. (2015) Bilateral Internal Mammary Artery Use for Coronary Artery Bypass Grafting Remains Underutilized: A Propensity-Matched Multi-Institution Analysis. The Annals of Thoracic Surgery, 100, 8-15. https://doi.org/10.1016/j.athoracsur.2015.02.088

[7] Barner, H. and Barnett, M. (1994) Fifteen to Twenty-One Year Angiographic Assessment of Internal Thoracic Artery as a Bypass Conduit. The Annals of Thoracic Surgery, 57, 1526-1528. https://doi.org/10.1016/0003-4975(94)90114-7

[8] Tector, A.J., Amundsen, S., Schmahl, T.M., et al. (1994) Total Revascularization with T Grafts. The Annals of Thoracic Surgery, 57, 33-38. https://doi.org/10.1016/0003-4975(94)90361-1

[9] Barra, J.A., Bezon, E., Mansourati, J., et al. (1995) Reimplantation of the Right Internal Thoracic Artery as a Free Graft into the Left in Situ Internal Thoracicartery (Y Procedure). One-Year Angiographic Results. The Journal of Thoracic and Cardiovascular Surgery, 109, 1042-1047. https://doi.org/10.1016/S0022-5223(95)70186-9

[10] Kamath, M.L., Matysik, L.S., Schmidt, D.H., et al. (1985) Sequential Internal Mammary Artery Grafts Expanded Utilization of an Ideal Conduit. The Journal of Thoracic and Cardiovascular Surgery, 89, 163-169. https://doi.org/10.1016/S0022-5223(19)38810-5

[11] Chocron, S., Etievent, J.P., Schiele, F., et al. (1994) The Y Graft: Myocardial Revascularization with Both Internal Thoracic Arteries: Evaluation of Eighty Cases with Coronary Angiographic Assessment. The Journal of Thoracic and Cardiovascular Surgery, 108, 736-740. https://doi.org/10.1016/S0022-5223(94)70301-9

[12] Sauvage, L.R., Wu, H.D., Kowalsky, T.E., Davis, C.C., Smith, J.C., Rittenhouse, E.A., et al. (1986) Healing Basis and Surgical Techniques for Complete Revascularization of the Left Ventricle Using Only the Internal Mammary Arteries. The Annals of Thoracic Surgery, 42, 449-465. https://doi.org/10.1016/S0003-4975(10)60557-7

[13] Paterson, H.S., Naidoo, R., Byth, K., Chen, C. and Denniss, A.R. (2013) Full Myocardial Revascularization with Bilateral Internal Mammary Artery Y Grafts. Annals of Cardiothoracic Surgery, 2, 444-452.

[14] Raja, S.G. (2019) Total Arterial Coronary Grafting: Outcomes, Concerns and Con- 
troversies. Vessel Plus, 3, 23. https://doi.org/10.20517/2574-1209.2019.05

[15] Manabe, S., Fukui, T., Shimokawa, T., Tabata, M., Katayama, Y., Morita, S., et al. (2010) Increased Graft Occlusion or String Sign in Composite Arterial Grafting for Mildly Stenosed Target Vessels. The Annals of Thoracic Surgery, 89, 683-687. https://doi.org/10.1016/j.athoracsur.2009.11.053

[16] Sugimura, Y., Toyama, M., Katoh, M., Kotani, M., Kato, Y. and Hisamoto, K. (2011) Outcome of Composite Arterial Y-Grafts in Off-Pump Coronary Artery Bypass. Asian Cardiovascular and Thoracic Annals, 19, 119-122. https://doi.org/10.1177/0218492311400101

[17] Glineur, D., Noirhomme, P., Reisch, J., El Khoury, G., Astarci, P. and Hanet, C. (2005) Resistance to Flow of Arterial Y-Grafts 6 Months after Coronary Artery Bypass Surgery. Circulation, 112, I281-I285. https://doi.org/10.1161/CIRCULATIONAHA.104.524702

[18] Benedetto, U., Montecalvo, A., Kattach, H., Amrani, M., Raja, S.G. and Harefield Cardiac Outcomes Research Group (2015) Impact of the Second Internal Thoracic Artery on Short- and Long-Term Outcomes in Obese Patients: A Propensity Score Matched Analysis. The Journal of Thoracic and Cardiovascular Surgery, 149, 841-7.e72. https://doi.org/10.1016/j.jtcvs.2014.08.060

[19] Kajimoto, K., Yamamoto, T. and Amano, A. (2015) Coronary Artery Bypass Revascularization Using Bilateral Internal Thoracic Arteries in Diabetic Patients: A Systematic Review and Meta-Analysis. The Annals of Thoracic Surgery, 99, 1097-1104. https://doi.org/10.1016/j.athoracsur.2014.09.045

[20] Kinoshita, T., Asai, T. and Suzuki, T. (2015) Off-Pump Bilateral Skeletonized Internal Thoracic Artery Grafting in Patients with Chronic Kidney Disease. The Journal of Thoracic and Cardiovascular Surgery, 150, 315-21.e3. https://doi.org/10.1016/j.jtcvs.2015.04.058

[21] Kinoshita, T., Asai, T., Suzuki, T., Kuroyanagi, S., Hosoba, S. and Takashima, N. (2012) Off-Pump Bilateral Skeletonized Internal Thoracic Artery Grafting in Elderly Patients. The Annals of Thoracic Surgery, 93, 531-536. https://doi.org/10.1016/j.athoracsur.2011.09.077

[22] Fouquet, O., Tariel, F., Desulauze, P. and Mével, G. (2015) Does a Skeletonized Internal Thoracic Artery Give Fewer Postoperative Complications than a Pedicled Artery for Patients Undergoing Coronary Artery Bypass Grafting? Interactive Cardio Vascular and Thoracic Surgery, 20, 663-668. https://doi.org/10.1093/icvts/ivv026

[23] Di Mauro, M., Iaco, A.L., Acitelli, A., D’Ambrosio, G., Filipponi, L., Salustri, E., et al. (2015) Bilateral Internal Mammary Artery for Multi-Territory Myocardial Revascularization: Long-Term Follow-Up of Pedicled versus Skeletonized Conduits. European Journal of Cardio- Thoracic Surgery, 47, 698-702. https://doi.org/10.1093/ejcts/ezu247

[24] Jones, E.L., Lattouf, O.M. and Weintraub, W.S. (1989) Catastrophic Consequences of Internal Mammary Artery Hypoperfusion. The Journal of Thoracic and Cardiovascular Surgery, 98, 902-907. https://doi.org/10.1016/S0022-5223(19)34269-2

[25] Raja, S.G. (2006) Composite Arterial Grafting. Expert Review of Cardiovascular Therapy, 4, 523-533. https://doi.org/10.1586/14779072.4.4.523

[26] Orlov, B., Gurevitch, J., Kogan, A., Rubchevsky, V., Zlotnick, A.Y. and Aravot, D. (2005) Multiple Arterial Revascularization Using the Tangential K-Graft Technique. The Annals of Thoracic Surgery, 80, 1948-1950. https://doi.org/10.1016/j.athoracsur.2004.05.071

[27] Nakajima, H., Kobayashi, J., Tagusari, O., Bando, K., Niwaya, K. and Kitamura, S. 
(2004) Competitive Flow in Arterial Composite Grafts and Effect of Graft Arrangement in Off-Pump Coronary Revascularization. The Annals of Thoracic Surgery, 78, 481-486. https://doi.org/10.1016/j.athoracsur.2004.03.003

[28] Gu, C.X., Yang, J.F., Zhang, H.C., Wei, H. and Li, L.K. (2012) Off-Pump Coronary Artery Bypass Grafting Using a Bilateral Internal Mammary Artery Y Graft. Journal of Geriatric Cardiology, 9, 247-251. https://doi.org/10.3724/SP.J.1263.2011.12251

[29] Glineur, D., Etienne, P.Y., Kuschner, C.E., et al. (2017) Bilateral Internal Mammary Artery Y Construct with Multiple Sequential Grafting Improves Survival Compared to Bilateral Internal Mammary Artery with Additional Vein Grafts: 10-Year Experience at 2 Different Institutions. European Journal of Cardio-Thoracic Surgery, 51, 368-375. https://doi.org/10.1093/ejcts/ezw282

[30] Di Mauro, M., Iacò, A.L., Allam, A., et al. (2016) Bilateral Internal Mammary Artery Grafting: In Situ versus Y-Graft. Similar 20-Year Outcome. European Journal of Cardio-Thoracic Surgery, 50, 729-734. https://doi.org/10.1093/ejcts/ezw100 